\title{
Coalitions and conflict: A longitudinal analysis of men's politics
}

\author{
Daniel Redhead ${ }^{1 *}$ (D) and Christopher R. von Rueden ${ }^{2}$ \\ ${ }^{1}$ Department of Human Behaviour, Ecology and Culture, Max Planck Institute for Evolutionary Anthropology, Deutscher \\ Platz 5, 04103 Leipzig, Germany and ${ }^{2}$ Jepson School of Leadership, University of Richmond, 221 Richmond Way, Richmond, \\ VA 23173, USA \\ ${ }^{\star}$ Corresponding author. E-mail: daniel_redhead@eva.mpg.de
}

\begin{abstract}
To negotiate conflict and navigate status hierarchy, individuals in many species form coalitions. We describe inter-personal conflicts and assess theories of coalition formation in a small-scale human society. Based on longitudinal and cross-sectional social network analysis of men in two communities of Tsimane forager-horticulturalists, we find evidence of reciprocity in coalitional support, as well as evidence of transitivity: an ally of my ally is likely to become my ally. We find mixed support for coalition formation between individuals who share a common adversary. Coalition formation was also predicted by food- and labour-sharing and especially by kinship. Physically formidable men and men higher in informal status were more likely to provide coalitional support over time; evidence was mixed that they receive more coalitional support. The highest status men are hubs of a dense coalitional support network that indirectly link all men in the community. These findings suggest that male coalition formation is multiply motivated, and in general reveals the political dynamics that structure men's lives in small, relatively egalitarian communities.
\end{abstract}

Keywords: Coalition formation; social status; conflict; hierarchy; egalitarianism

Social media summary: Among the Tsimane, the emergence of coalitions over time is primarily motivated by social status and existing social relationships between individuals.

\section{Introduction}

The politics of animal societies often involves coalition-based competition. This is true of ravens, social carnivores, dolphins, elephants and many primates (Bissonnette et al., 2015). Coalitions can be defined as two or more individuals who cooperate against a third party, be it an individual or rival coalition (Harcourt et al., 1992). The formation and coordination of coalitions are computationally demanding, which may have limited the frequency of their evolution in group-living animals. For example, coalition formation can require tracking changes in within-group loyalties as well as changes in individuals' relative competitiveness (Silk, 1999; Perry et al., 2004; Young et al., 2014; Pietraszewski, 2016).

Principal motivations for coalition formation are to gain or maintain one's status rank relative to others or to exacerbate or attenuate status inequality even if relative ranks remain unchanged. In chimpanzees, male participation in coalitions with higher ranking males associates with increased mating opportunity relative to individuals of a similar rank, as well as gains in rank over time (Duffy et al., 2007; Gilby et al., 2013; Watts, 2018). Across many primate species, subordinates also form 'levelling' coalitions to weaken higher ranking individuals' privileged access to resources or mates (Pandit \& van 
Schaik, 2003). The political and reproductive egalitarianism of small-scale human societies may owe in large part to levelling coalitions that are larger, more effective, and longer-lasting (Boehm, 1999; Gavrilets et al., 2008).

Kin are a primary source of coalitionary support. The available pool of coalition partners may be biased towards kin, kinship may affect coalitional synergy and relatedness to coalition partners may increase the returns to conflict victory as a result of inclusive fitness benefits (Bissonnette et al., 2015). Where contest competition is strong, the common primate pattern is that the philopatric sex (typically females) forms kin-based coalitions to enforce hierarchies (Van Schaik, 1989). Where contest competition is intermediate and benefits to helping kin are weaker, hierarchies are more likely to be structured by individual competitiveness than kin-based coalitions (Broom et al., 2009).

An assumption of many coalition-formation models is that the joint competitiveness of coalition members relative to their target's competitiveness determines the coalition's success, so individuals should be sensitive to the relative competitiveness of potential coalition partners, such as their dominance rank or physical formidability (Bissonnette et al., 2015). Many empirical studies support this prediction, including studies of non-human primates (Silk, 1999; Perry et al., 2004; Young et al., 2014) and experimental studies in humans (Benenson et al., 2009; Barbaro et al., 2018). Coalitions are also built via exchange. For example, male chimpanzees may exchange meat (Nishida et al., 1992) or grooming (Watts, 2002) for support in conflicts. Exchange of food for coalitionary support among males has also been described in small-scale human societies (Patton, 2005). Female-female coalitions are largely limited to female philopatric species. Female bonobos are an interesting exception, surmounting their lack of kinship to form coalitions that thwart male aggression. While female bonobos frequently exchange sex and grooming, there isn't strong evidence that female bonobo coalitions are built upon such exchange (Tokuyama \& Furuichi, 2016).

Humans form coalitions as a principal means of competing for, and regulating others', social status (Boehm, 1999; Tooby et al., 2006; von Rueden et al., 2008). The relatively larger scale and efficacy of human coalitions may be due to cognitive abilities, such as language (Smith, 2003) and joint attention (Tomasello et al., 2005), which increase awareness of ongoing conflicts, increase ability to effectively intercede in conflicts on another's behalf and decrease the decay rate of affinities among coalition members (Gavrilets et al., 2008). Largely monogamous pair bonding between males and females was also a likely ingredient in the evolution of human coalitions (Chapais, 2009). Pair bonding reduces mate competition between prospective coalition partners and, among males, allows for more efficient recognition of kin for coalition building. Furthermore, affinal kinship ties create shared interests among previously unrelated individuals or communities (Chapais, 2009) and can be as important as consanguineal kinship ties in gaining or maintaining status (Hughes, 1988; Walker et al., 2013; Macfarlan et al., 2014). Thus, marriage can be an important strategy for building or cementing coalitions.

In human societies, women and men often differ in the structure and function of their same-sex coalitions. Men have been more likely to value, build and participate in large coalitions, often involving non-kin, in the service of intra-group coalitional competition (Low, 1992; Smuts, 1995) and intergroup warfare (McDonald et al., 2012; Glowacki et al., 2017). Several studies in industrialized societies suggest that women's same-sex coalitions tend to be smaller in size, less ostensibly hierarchical owing to greater enforcement of egalitarianism and slower to reconstitute once broken apart (Benenson, 2019; David-Barrett et al., 2015; Liesen, 2013; Vigil, 2007). Sexual selection may contribute to these average sex differences in coalition building, whether directly via a sex-specific coalitional psychology or indirectly via the influence of sexually selected reproductive strategies on culturally transmitted gender norms (von Rueden et al., 2018). Such norms specify the behaviour that is expected of women and men, particularly in the context of a sexual division of labour. In the majority of human societies, men are expected to engage in more labour outside of the household and women in more intra-household labour, including childcare. Sexual divisions of labour and associated cultural norms may frequently limit the extent of women's coalition-building relative to men, particularly with non-kin (von Rueden et al., 2018). 
In the Amazonian community we analyse in the present study, von Rueden et al. (2018) previously found that men tend to have more cooperation partners than women, men tend to cooperate in larger groups and a much larger fraction of men's cooperation partners are same-sex (70 vs. 44\%) and nonkin (21 vs. 7\%). Furthermore, men's leveraging of their social relationships for coalitional support is generally more conspicuous, particularly during the mixed-sex community meetings in which much of the community politics play out (von Rueden et al., 2018). These sex differences support evaluation of men's and women's coalition-formation separately. However, the principal reason we exclude women from the present analysis is that we currently lack longitudinal data on women's coalitions and conflicts.

\section{Predictions}

To better understand the factors that shape coalition formation in small-scale societies, particularly among men, we investigated coalition dynamics among men in a Tsimane community in Amazonian Bolivia. We use longitudinal social network analysis to quantify the contributions of structural network properties, existing relationships and individual attributes on the probability of a coalition tie forming between two individuals. By coalition tie, we mean the likelihood that one man names another man as someone who comes to his aid during conflicts. Conflicts infrequently involve physical aggression; most often they are limited to verbal disputes. We also conduct a cross-sectional social network analysis in a second Tsimane community to compare with the results of our longitudinal analysis (See Supplementary Materials for more information about our cross-sectional analyses).

We investigate several structural effects within the coalition networks. We predict (1) reciprocity in naming someone as a coalition partner. We also examine predictions from structural balance theory (Heider, 1982; Rawlings \& Friedkin, 2017), which posits that certain triadic configurations are more likely to form than others within the networks. In particular, we predict that (2) an ally of a man's ally is likely to also become his ally and (3) men in conflict with the same individual are likely to become allies.

We analyse the multiplex (cross-network) effects of two other existing relationships on the probability of a man naming another man as a source of support during conflict. We predict that (4) food-and labour-sharing and (5) close kinship (a composite of consanguineal and affinal close kin) increase the probability of a coalition tie. Men gain fitness benefits from supporting not just consanguineal kin but also affinal kin and non-kin exchange partners, because of the inter-dependence that affinal kinship and exchange generate (Aktipis et al., 2018). For example, brothers-in-law share fitness interests in each other's offspring, and thus in each other's well-being. Across small-scale societies, men on whom both consanguineal and affinal relatedness are concentrated tend to be higher status in their communities (Hughes, 1988; Walker et al., 2013), perhaps in part because they can draw on greater coalitional support. Furthermore, a composite measure of consanguineal and affinal relatedness may often best predict which individuals remain together following kin group fission (Hughes, 1988).

The individual attributes we analyse include physical formidability (a composite of height, weight and upper body strength) and social status (a composite of informal political influence and respect within the community). Because these attributes increase the market value of potential coalition partners, we predict that (6) more physically formidable or higher status individuals should be more likely to be aided by others during conflicts. We also predict that (7) higher status individuals are more likely to aid others during conflicts, because maintaining or gaining social status may be dependent on not just receiving but also providing help in resolving conflicts, if not providing more partisan coalitional support. In our previous work with the Tsimane, we showed that higher status men are most likely to gain food- and labour-sharing partners over time. While sharing partners do not tend to assort on the basis of status, cooperation with higher status men increases a man's own status over time (von Rueden et al., 2019). We argue that the uniquely human dependence of status on prestige (i.e. a reputation for being able and willing to deliver unique benefits to others) contributed to the evolution of cooperation and egalitarianism in human societies. 
In the current analysis, we also predict that (8) high status men are more likely to experience conflict, for several potential reasons. They may be less wary of the consequences of conflict and more likely to win conflicts or get drawn into conflicts they attempt to mediate. Higher status Tsimane men are more frequent mediators of inter-personal conflicts within their communities (Glowacki \& von Rueden, 2015). Higher status men may also provoke envy or levelling behaviour on the part of lower status men. Among the highly egalitarian Ju'hoansi hunter-gatherers, higher status individuals, including camp leaders and skilled producers, were more likely than others to both initiate and to be targets of public criticism or other punishment (Wiessner, 2005).

\section{Methods}

\section{Ethnographic setting}

The Tsimane live in villages ranging from 50 to 500 individuals in the neotropics of central, low-land Bolivia. Their economy is based on swidden horticulture (plantains, manioc, rice and corn), hunting, fishing and fruit gathering. Men do the large majority of hunting while women do the large majority of direct childcare and food processing. Both participate substantially in horticultural production. Food sharing and collabouration in productive activities tend to be concentrated within extended families residing in the same or nearby households (Hooper et al., 2015). After marriage, men often reside near the household of their parents-in-law. However, men rarely lack consanguineal kin in the community, since marriages tend to occur between community members, and men will otherwise tend to marry into communities where a sibling already resides.

The Tsimane remained largely unconnected to Bolivian society until the mid-twentieth century, when a new wave of missionaries and a road from the highlands arrived. Average income is less than 2 US dollars per day from the sale of horticultural products and sporadic wage labour with loggers and ranchers.

The Tsimane have no recent history of inter-group warfare. Within villages, dyadic conflicts tend to be resolved by the parties directly involved, sometimes with the aid of close kin and other coalition members. For many of the conflicts that remain unresolved, other third parties within the village may step in to help mediate. This includes the corregidor, who is elected to represent the village's interests with outsiders and to coordinate meetings (von Rueden et al., 2014). Village meetings often involve mediation of more intractable conflicts, coordination of communal work like village trail-clearing and discussion of joint projects with the Bolivian government or non-governmental organizations. During meetings or smaller gatherings, vocal support from allies is a principal means by which men swing opinion in their favour.

The following dialogue is an example of conflict over land for horticultural purposes that is frequent in Tsimane communities. Conflicts over land are frequent in that land is not formally owned by individuals and population growth has increased demand for access to nearby forest for horticultural purposes. Two members of the longitudinal study community, Julio and Manuel, had begun planting in an area where another community resident, Miguel, argued he had first staked a claim. The ensuing conflict was discussed in a community meeting by those involved in the conflict and by several other attendees. Names are changed to retain anonymity.

Miguel: When I first married my wife, I made my field near here because I want to live with my family. But now my father-in-law lives in this place. So I moved to the place where I am now. I have already cut five hectares out of the forest, where I have a field and a house. Now, others want to use my land, and I don't want to fight with my neighbors. They thought that if they planted banana trees I wouldn't cross into their field. I just want them to give me 200 meters, that's all.

Juan: I also know that when Miguel moved over there he made his field by that lagoon. I helped him cut down all the trees. The field first belonged to Miguel, not to Julio or Manuel. First it was Miguel's. 
Miguel: I have already planted where I live now. I have asked Benicio to help me tell other people not to move into the place where I now live. Let them look somewhere else, in another part of the forest.

Juan: As Miguel said, where we now have our fields others should not plant. Go over and look at it all so you will know. Because we can't live anywhere else.

Benicio: The soil needs us now; we must begin to work because our families will be hungry. The soil does not grow without us. We need it to survive.

Both Benicio and Juan are allies of Miguel and are in support of his claim to disputed land. Julio and Manuel did not voice their views in the meeting, probably because they sensed a relative lack of coalitional support for their cause.

\section{Data collection}

In one Tsimane village (village 1), three waves of panel data were collected from the entire adult male population aged 21 years and older. Data were collected in 2009()$, 2014(n=83)$ and $2017(n=90)$. Data were collected through structured interviews to generate social networks and status rankings. In 2008, the panel data was also collected from the entire adult male population in a second Tsimane community (village 2, $n=89$ ). See Supplementary Materials for further information about village 2 .

\section{Social networks}

Social network data were constructed using a name generator approach. This entailed that all adult men living in the village that year were asked to freelist others in the community. These self-report nomination data were combined to create a sociocentric and binary graph with $1 \mathrm{~s}$ in the matrix indicating the presence (and 0s an absence) of a tie between individuals. Since the social network measures solicit responses on participants' perceptions of their social relationships, the networks are directed graphs and, thus, all ties are not expected to be reciprocal. Coalition networks were constructed by asking participants to freelist 'who comes to your aid when you are in a conflict with others?' Conflicts were captured by asking participants to freelist 'who have you been in a conflict with during the past year?' Participants were also asked to describe the conflicts they reported and whether anyone helped mediate the conflict. Subsequently, CvR used the text of participants' responses to subjectively categorise their reported conflicts, as depicted in Figure 1. Our food- and labour-sharing network was generated by asking participants who shares food with them or assists them in hunting, fishing or horticultural labour. Participants were asked about each of these domains of cooperation separately, but nominations were combined by taking their union, such that any nomination in a given domain of food- and labour-sharing was treated as a binary tie between the participant and the nominated individual.

\section{Photo rankings of social status}

At every wave of data collection, approximately one-third of adult men were randomly selected to rank Polaroid ${ }^{\mathrm{TM}}$ photographs of other adult men in the village. Each of these individuals was instructed to rank two sets of photographs for each of several separate dimensions of social status within the community. These dimensions include 'whose voice carries more weight during community debates' and 'who is more respected'. Peer-ratings can be an efficient and accurate method for producing quantitative data from local knowledge (Reyes-García et al., 2016; Stibbard-Hawkes et al., 2018), especially for a public, positional good-like status. Furthermore, studies of the Tsimane and other small-scale societies find that peer-rated status correlates strongly with observational measures of status (von Rueden et al., 2018; Werner, 1981).

The photos presented to participants showed only the top half of each man's body and were set against as neutral a background as possible. Photos were numbered, and the photos chosen for a 


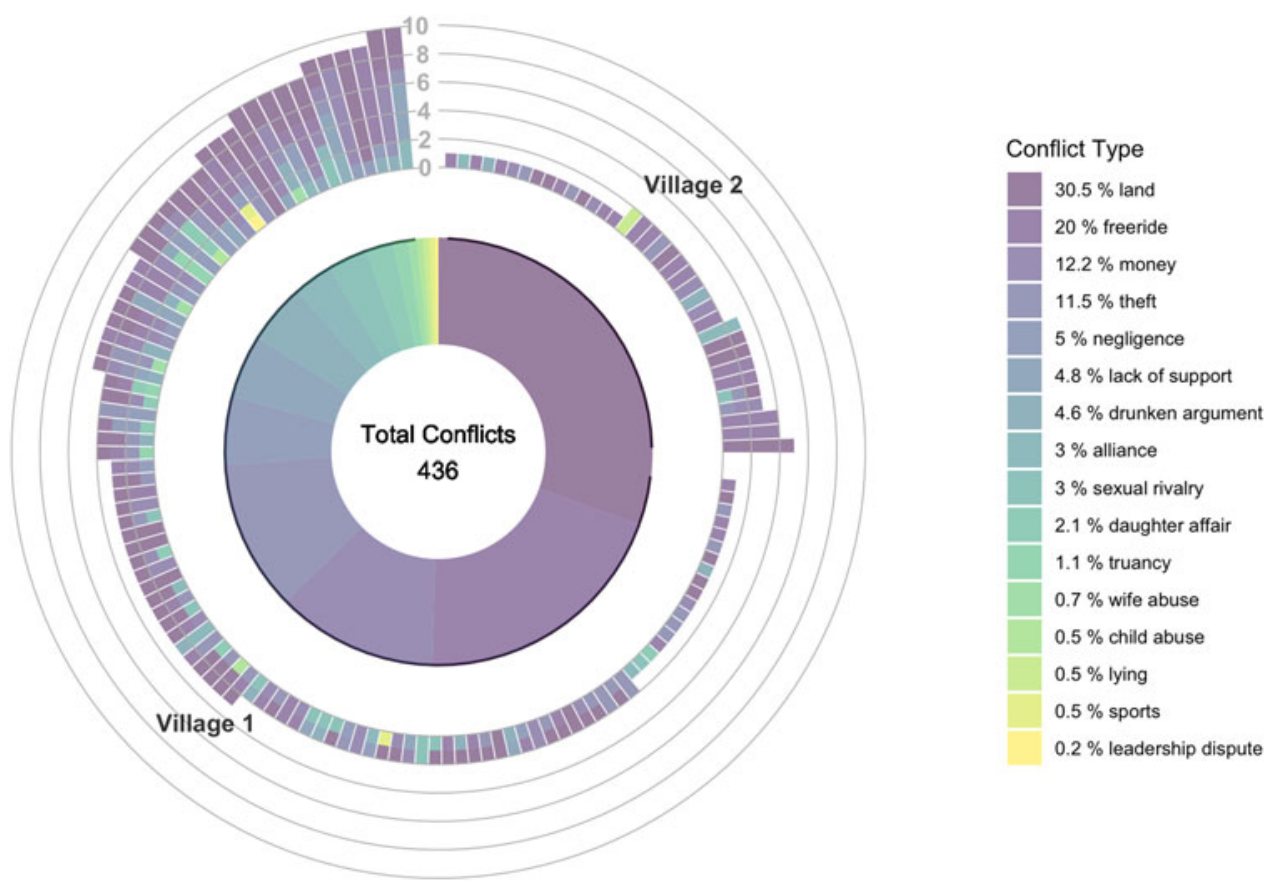

Figure 1. Outline of types of observed conflicts. The inner doughnut chart describes the proportion of types of conflicts across the entire sample, with corresponding\%ages reported in the key. The outer radial bar-chart depicts individual-level information on conflicts, with each bar representing an individual, and the length of the bar pertaining to the number of conflicts that the individual was involved in. The colour of these bars represents the types of conflict that the individual was involved in and corresponds to the categories outlined in the key.

particular set corresponded to the row vectors in a matrix based on a projective plane (von Rueden et al., 2008, 2019). Such matrices keep the number of vectors and numbers per vector to a minimum, while ensuring that a pair of numbers appear together in the same vector only once. Based on this approach, each man's photo was ranked nine times in 2009, each time in a set with eight other photos with whom he had not yet been compared. Thus, each man could receive a score on each status dimension ranging from 9 (lowest) to 81 (highest). In 2014 and 2017, a larger matrix was used to account for growth in community size, such that each man was ranked 10 times, each time in a set with nine other photos with whom he had not yet been compared. The photo-ranked scores from 2014 and 2017 were transformed to match the potential range in scores (9-81) from 2009.

All sets of photographs presented to participants were shuffled into a random order and participants were asked to rearrange the photographs into a line of photographs that they believed to best represent the relative ranking of individuals within the array. No ties between photographs were allowed, and no participant was presented with a photograph set which contained their own photo. We combined the photo-ranked status dimensions into a single variable (status), as suggested by a maximum-likelihood factor analysis (von Rueden et al., 2019) and normalized status such that the variable ranged between 0 and 1 .

\section{Other covariates}

Every 1-3 years during the study period, clinicians associated with the Tsimane Health and Life History Project (http://www.unm.edu/ tsimane) measured participants' height and weight with a portable stadiometer and a digital weigh scale, respectively. Shoulder and chest strength were measured with a Lafayette Manual Muscle Tester and grip strength was measured with a Smedley III dynamometer. We summed these values to create a composite upper body strength measure. A maximum- 
likelihood factor analysis indicated that height, weight and upper body strength comprised distinct factors with adequate internal consistency. We then standardized and averaged these measures to assess them as a single covariate ('physical formidability') that captures physical strength and size.

Demographic data used to determine kinship were retrieved from reproductive history interviews first collected in 2003-2005 and updated during the study period. Individuals were analysed as close kin if they were brothers, father and son, brothers-in-law, or father and son-in law. This categorical measure captures the concentration of Tsimane economic and social life within household clusters, where men live near their own parents and siblings or, particularly early in marriage, near their wives' parents and siblings. While the close kin measure does not capture weaker kin ties, the range for men's number of close kin is large, from $0 \%$ up to $18.5 \%$ of all adult men age 21 years and older in village 1 . See Table 1 for more descriptives.

\section{Analytical strategy}

We implemented a stochastic actor-oriented model (SAOM) to assess the development of our coalition network in village 1 over the 8 year period, and a stationary SAOM to analyse our cross-sectional coalition network in village 2 (see Supplementary Materials for more information and results; Snijders \& Steglich, 2015). Our models were estimated using the RSiena package (version 1.2-25; Ripley et al., 2020) in R (v3.6.3; Team, 2013). SAOMs are a type of agent-based simulation model that assess latent, unobserved change in a network over continuous time, which is calibrated by observed networks that have been measured at discrete points in time. Within the model, a rate function measures the opportunities for individuals to make sequential changes to the states of their outgoing ties, and the probabilities of any given tie change are measured by a linear combination of effects contained in an objective function (Snijders, 1996). These effects can be endogenous (i.e. structural processes internal to the network) and may depend upon individual and dyadic covariates or specify associations between different networks.

\section{Model specification}

In the current research, we assessed coalition ties as a dependent network. We included endogenous parameters for outdegree, reciprocity, indegree popularity, outdegree activity and shared popularity. The outdegree parameter is similar to the intercept of a regression model and assesses the number of outgoing ties, while reciprocity measures the tendency for individuals to reciprocate ties over time, and the indegree popularity and outdegree activity parameters examine the tendency for indegree (and outdegree) to predict future indegree (and outdegree) ties. We also included a shared popularity term, that assesses the tendency for individuals to gain ties with the same set of other individuals (Robins et al., 2009).

To assess our predictions stemming from balance theory, we included a parameter to assess transitive group formation (GWESP: geometrically weighted edgewise shared partners). More specifically, if individual $i$ is a coalitional partner with individual $h$, and individual $h$ is a coalitional partner with individual $j$, then over time individual $i$ is more likely to nominate individual $j$ as a coalitional partner. We also included a mixed closure with conflict parameter, which captures the process whereby if individual $i$ has a conflict with individual $h$, and individual $h$ has a conflict with individual $j$, then individual $i$ is more likely to form a coalition with individual $j$.

To examine the roles of social status and physical formidability in coalition formation, we included parameters for indegree (alter), outdegree (ego) and covariate similarity. We also included indegree and outdegree parameters specific to the community corregidor. Although this elected position was held by a different individual at each time point, the corregidor was always the most frequently nominated source of coalitional support. A principal expectation of the corregidor is that he dispassionately assists in dispute resolution when called upon. Moreover, we specified dyadic effect parameters that capture the direct effects that kinship and food- and labour-sharing have on coalition formation. 
Table 1. Network descriptive statistics for village 1

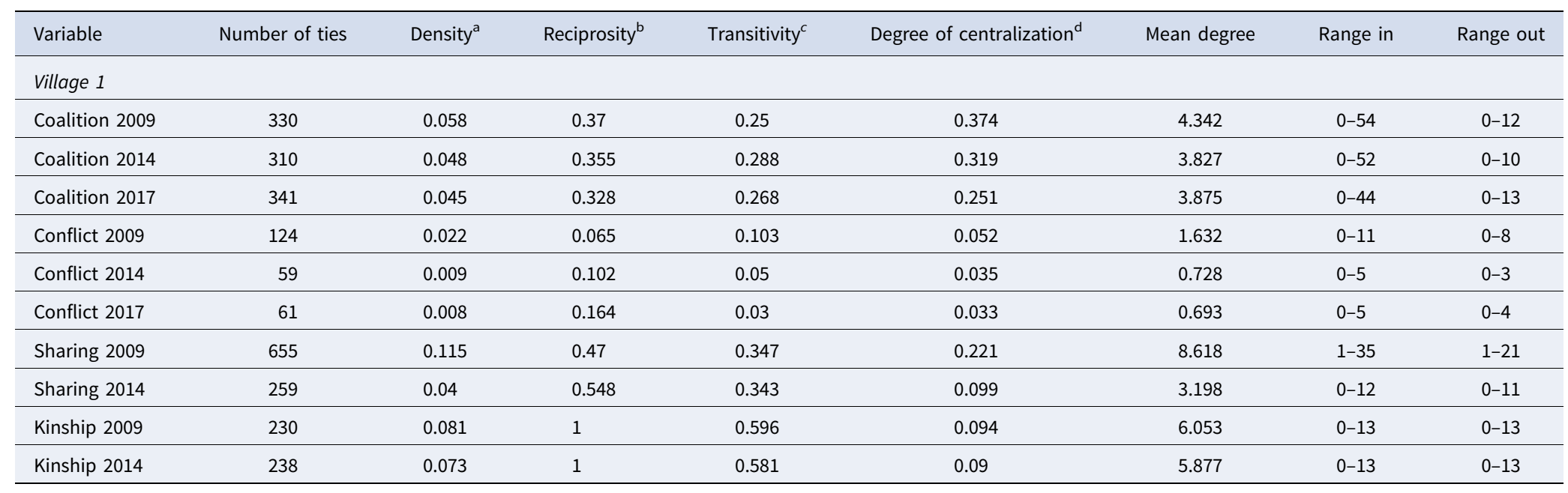

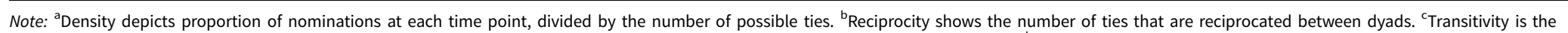

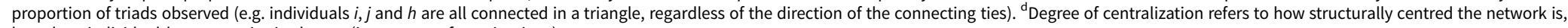
based on individual heterogeneity in degree (i.e. counts of nominations). 


\section{Network composition and missing values}

Among the Tsimane, migration between communities is relatively common and, given the large timescale of the current research, a non-trivial proportion of individuals aged into our adult male category between our points of observation. To account for this change in network composition, we use the Huisman-Snijders method of joiners and leavers (Huisman \& Snijders, 2003). Owing to the large proportion of change observed across time points - likely caused by severe flooding in 2014 and also by changing sample composition - we fixed the rate parameter for the period between our initial observations of data (period 1: 2009-2014) to allow adequate model convergence. We further included several time dummies for our model parameters to account for time heterogeneity observed across observation periods (following a forward-selection approach recommended by Lospinoso et al., 2011). Given this, we report estimates for period 1 (2009-2014) and period 2 (2014-2017) for certain (time heterogeneous) parameters separately in the relevant figures, tables and text in our Results section. Missing values (total $8.5 \%$ ) for status (2\%) and physical formidability (11.5\%) were imputed using a Bayesian copula approach (Hoff, 2018). See (Hollenbach et al., 2018) for an overview and comparison with other multiple imputation methods.

\section{Results}

\section{Descriptive statistics}

Before making any inferences about intragroup coalitions within our study community, we describe the conflicts reported by community members. While we do not know what fraction of reported conflicts precipitated coalitional support, in the majority of conflicts (55\%) respondents cited intervention by informal, third-party mediators. The difference between coalitional support and mediation is not clear-cut. Mediators are expected to be non-partisan, although this is not always the case. Thus, when nominating others as sources of coalitional support, individuals were probably including mediators as well as more clearly partisan supporters.

As shown in Figure 1, there were a total of 436 conflicts observed in village 1 in 2009, 2014 and 2017 - and village 2 in 2008 - and individuals were, on average, involved in 1.98 conflicts. Most of these conflicts were due to disputes over access to land (30.5\%), perceived free-riding such as selling lumber from community forest without consent (20\%), money owed (12.2\%) and theft (11.5\%). Another notable category of conflict was failure to support a coalition member in the context of another conflict, which accounted for $4.6 \%$ of all conflicts. In one time wave (2014), individuals also reported whether their conflicts ever precipitated physical violence: 12 of 87 conflicts (13.8\%) at some point involved a physical fight.

In the initial wave of observation (2009) in village 1, individuals on average either made or received roughly one conflict nomination. Conflict nominations decreased over time in village 1 , while within time-waves the proportion of conflicts in which both parties nominated one another increased (i.e. network reciprocity: see Table 1). Minimal network reciprocity in conflict nominations, within timewaves, is consistent with other studies, where negative ties tend to be reciprocated less than positive ties, e.g. 34 vs. $5 \%$ in rural Honduran villages (Isakov et al., 2019), and $60-80$ vs. $10-20 \%$ in a massively multiplayer online game (Szell et al., 2010).

The small number of conflict nominations and low temporal stability to the conflict network precluded our ability to include conflict as a dependent network in our analyses. Thus, as a test of prediction (8), we present only descriptive bivariate correlations between status and conflict indegree and outdegree (see Supplementary Materials Figure 2). In village 1, status at all points of observation has a moderate association with receiving conflict nominations $(r=0.37-0.57)$, while the associations it has with sending conflict ties are much smaller $(r=0.05-0.32)$.

Descriptive statistics indicate that our coalition networks are relatively sparse, with between 310 and 344 nominations in village 1 and individuals, on average, sending or receiving 4.02[0-54] nominations across the three points of observation. Table 1 outlines descriptive network statistics that characterise 
(a)

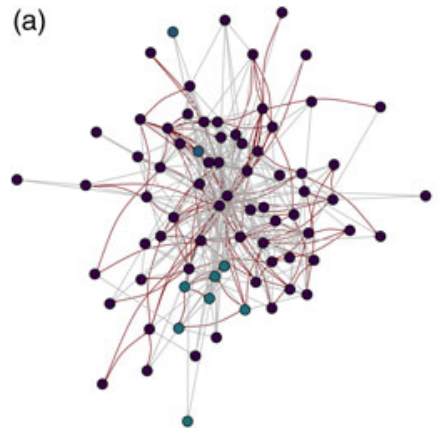

(b)

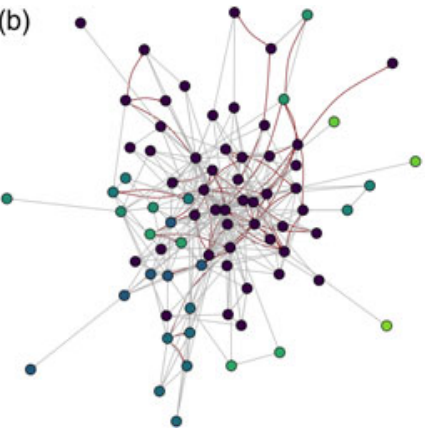

(c)

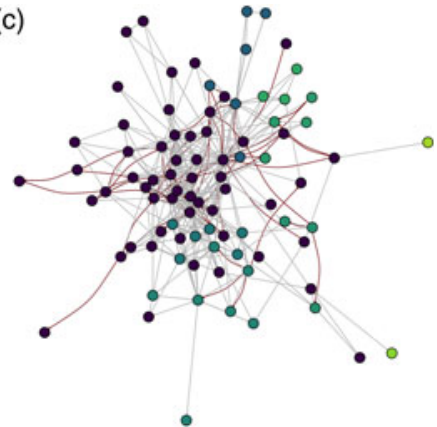

Figure 2. Network digraphs of the coalition networks observed in 2009, 2014, and 2017. Nodes (circles/individuals) are coloured by the community that they have been assigned to by the MAP equation (Rosvall and Bergstrom, 2008). Coalition ties are coloured grey and conflict ties red.

coalitions in village 1 . Coalitions seem to be described by a moderate amount of clustering (global transitivity) centred on particular men (degree centralization). We further assessed the community structure within the coalition network using the Map Equation (Rosvall \& Bergstrom, 2008; Rosvall et al., 2009) in the R package, igraph (v.1.2.5, Csardi et al., 2006). More specifically, the Map Equation is a flow-based community detection algorithm that classifies individuals into subgroups of densely connected individuals. For a detailed outline of this procedure see Rosvall et al. (2009). As visualised in Figure $2 \mathrm{a}-\mathrm{c}$, our coalition networks in village 1 constitute one large community of 67 (2009), 49 (2014) and 56 (2017) densely connected individuals, and several peripheral groups consisting of between two and seven individuals. See Supplementary Materials for descriptive information about the coalition network in Village 2.

\section{Longitudinal analysis}

Refer to Table 2 and Figure 3 for parameter estimates $(\hat{\beta})$, standard errors $(S E)$, $p$-values $(p)$, odds ratios (OR) and confidence intervals (CI) for our stochastic actor-oriented model of coalition formation over time in village 1 . Refer to Supplementary Materials for full results of the cross-sectional SAOM in village 2 .

\section{Within-network results}

Our results suggest that there was a general tendency for individuals to be selective when naming coalition partners (outdegree: $\mathrm{OR}=0.07, \mathrm{CI}=[0.04-0.14]$ ). The coalition network was further characterised by substantial indegree differentiation $(\mathrm{OR}=1.32, \mathrm{CI}=1.17-1.48)$, and relative homogeneity in outdegree nominations $(\mathrm{OR}=0.82, \mathrm{CI}=[0.68-0.98])$. Alongside this, individuals were marginally less likely to receive nominations from those who were structurally equivalent (i.e. held similar positions within the network: $\mathrm{OR}=0.98, \mathrm{CI}=[0.97-1.00]$ ). Taken together, these findings suggest that, while individuals generally tended to list a similar number of coalition partners, we observe a so-called Matthew effect, where an individual's indegree popularity propagates their future popularity, and where these popular individuals tend to be nominated by different sets of others.

In support of prediction (1), individuals also tended to reciprocate nomination of each other as coalition partners over time $(\mathrm{OR}=2.59, \mathrm{CI}=[2.02-3.32])$. In line with prediction (2) relating to balance theory, we found that individuals formed coalitions through transitive processes $(\mathrm{OR}=2.87, \mathrm{CI}=$ [2.15-3.82]). This suggests that if individual $i$ named individual $h$ as a coalition partner, and individual $h$ named individual $j$, individual $i$ was subsequently more likely to name individual $j$ as a coalition partner. 
Table 2. Estimates of the longitudinal stochastic actor-oriented model

\begin{tabular}{|c|c|c|c|c|c|}
\hline Parameter & $\hat{\beta}$ & SE & $p$ & OR & $\mathrm{Cl}$ \\
\hline Rate: $2009-2014$ (fixed) & 40.00 & - & - & - & - \\
\hline Rate: 2014-2017 & 79.77 & 35.49 & 0.025 & - & - \\
\hline Outdegree & -2.68 & 0.35 & $<0.001$ & 0.07 & $0.03-0.14$ \\
\hline Reciprocity & 0.95 & 0.13 & $<0.001$ & 2.59 & $2.02-3.32$ \\
\hline Transitive group formation (GWESP) ${ }^{a}$ & 1.05 & 0.15 & $<0.001$ & 2.87 & $2.15-3.82$ \\
\hline Shared popularity & -0.02 & 0.01 & 0.025 & 0.98 & $0.97-1.00$ \\
\hline Indegree popularity (sqrt) & 0.28 & 0.06 & $<0.001$ & 1.32 & $1.17-1.48$ \\
\hline Outdegree activity (sqrt) & -0.20 & 0.09 & 0.030 & 0.82 & $0.68-0.98$ \\
\hline Mixed closure with conflict (2009-2014) & 0.01 & 0.19 & 0.939 & 1.01 & $0.70-1.46$ \\
\hline Mixed closure with conflict (2014-2017) & 1.33 & 0.38 & $<0.001$ & 3.79 & $1.81-7.93$ \\
\hline Main effect of kinship & 0.74 & 0.09 & $<0.001$ & 2.10 & $1.77-2.50$ \\
\hline Main effect of sharing (2009-2014) & 0.18 & 0.10 & 0.071 & 1.19 & $0.99-1.44$ \\
\hline Main effect of sharing (2014-2017) & 0.92 & 0.16 & $<0.001$ & 2.52 & $1.84-3.46$ \\
\hline Status indegree & 0.64 & 0.23 & 0.005 & 1.90 & $1.21-2.99$ \\
\hline Status outdegree (2009-2014) & 0.71 & 0.27 & 0.009 & 2.03 & $1.19-3.48$ \\
\hline Status outdegree (2014-2017) & -1.33 & 0.29 & $<0.001$ & 0.27 & $0.15-0.47$ \\
\hline Status similarity & 0.23 & 0.20 & 0.237 & 1.26 & $0.86-1.86$ \\
\hline Physical formidability indegree (2009-2014) & $<0.01$ & $<0.01$ & 0.020 & 1.00 & $1.00-1.01$ \\
\hline Physical formidability indegree (2014-2017) & -0.02 & $<0.01$ & $<0.001$ & 0.98 & $0.98-0.99$ \\
\hline Physical formidability outdegree & 0.01 & $<0.01$ & 0.012 & 1.01 & $1.00-1.01$ \\
\hline Physical formidability similarity & 0.19 & 0.22 & 0.385 & 1.21 & $0.79-1.85$ \\
\hline Corregidor indegree (2009-2014) & -0.75 & 0.16 & $<0.001$ & 0.47 & $0.34-0.65$ \\
\hline Corregidor indegree (2014-2017) & 1.37 & 0.33 & $<0.001$ & 3.94 & $2.07-7.51$ \\
\hline Corregidor outdegree & -0.38 & 0.25 & 0.131 & 0.68 & $0.42-1.12$ \\
\hline
\end{tabular}

Note: Our indegree parameters denote the tendency for an individual to be named by others as providing coalitional support, while outdegree denotes the likelihood that an individual names others as providing coalitional support. Similarity denotes the tendency for individuals to name others as providing coalitional support who score similarly on that covariate. Estimates for time periods one (2009-2014) and two (2014-2017) appear separately only where there were substantial time heterogeneous effects.

${ }^{\mathrm{a}}$ Geometrically weighted edgewise shared partners, with $\alpha=0.69$.

\section{Cross-network results}

Our findings suggest that the direct associations between the coalition network and other social networks helped guide nominations. However, these cross-network results indicate non-trivial time heterogeneity between points of observation. In period one (2009-2014), there was no real pattern of mixed transitive closure between coalition and conflict ties $(\mathrm{OR}=1.01, \mathrm{CI}=[0.70-1.48])$. In period two (2014-2017) and in support of prediction (3), we do observe transitive closure between coalition and conflict ties $(\mathrm{OR}=3.79, \mathrm{CI}=[1.81-7.93])$, such that if individual $i$ was in conflict with individual $h$, and individual $h$ was in conflict with individual $j$, then individual $i$ was subsequently more likely to form a coalition tie with individual $j$. In period one (2009-2014), food- and labour-sharing had a marginal direct association $(\mathrm{OR}=1.19, \mathrm{CI}=[0.99-1.44])$ with choice in coalition partners. In period two (2014-2017) and in support of prediction (4), our results highlight that there was an increased tendency for individuals to form coalitions with their sharing partners $(\mathrm{OR}=2.52, \mathrm{CI}=[1.84-3.46])$. 


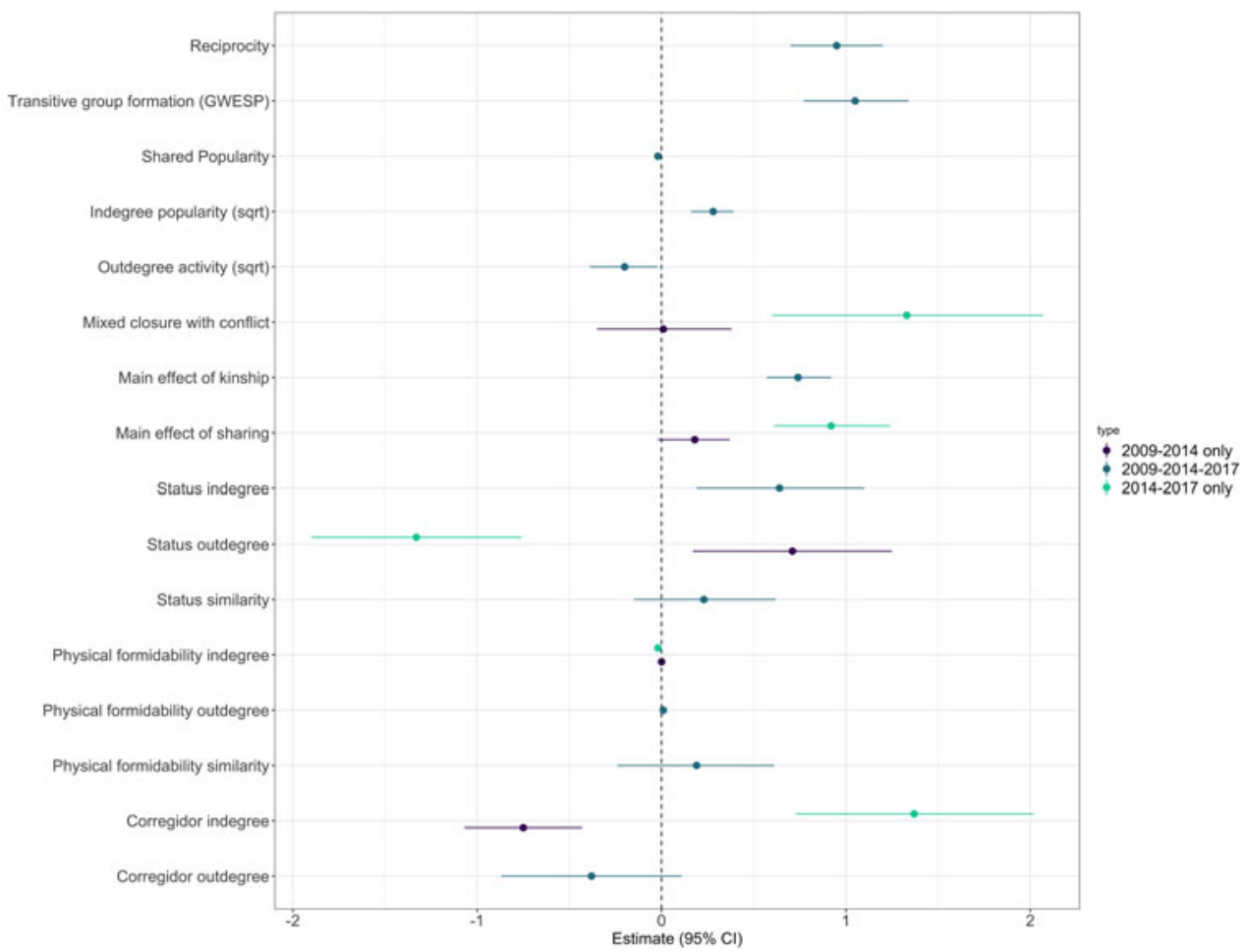

Figure 3. Forest plot of odds ratios and confidence intervals for parameters included in the longitudinal analyses. Our indegree parameters denote the tendency for an individual to be named by others as providing coalitional support, while outdegree denotes the likelihood an individual names others as providing coalitional support. Similarity denotes the tendency for individuals to name others as providing coalitional support who score similarly on that covariate. Estimates for time periods one (2009-2014) and two (2014-2017) appear separately only where there were substantial time heterogeneous effects.

Across the entire study in village 1, coalitions were substantially more likely to form between close kin $(\mathrm{OR}=2.10 . \mathrm{CI}=[1.77-2.50])$, per prediction $(5)$.

\section{Covariate results}

There is contradictory support for prediction (6). In time period one (2009-2014), high status men were more likely to name coalition partners $(\mathrm{OR}=2.03, \mathrm{CI}=[1.19-3.48])$, whereas in period two (2014-2017), high status men were less likely to name coalition partners (OR $=0.27, \mathrm{CI}=[0.15-$ 0.47]). In support of prediction (7), our results suggest that those high in status were more likely to be named as coalition partners over time, across both time periods ( $\mathrm{OR}=1.90, \mathrm{CI}=[1.21-2.99])$. In addition, physically formidable men were slightly more likely to be named as coalition partners in period $1(\mathrm{OR}=1.00, \mathrm{CI}=[1.00-1.01])$, but slightly less likely to be named in period $2(\mathrm{OR}=$ $0.98, \mathrm{CI}=[0.98-0.99])$. Across both time periods those high in physical formidability were slightly more likely to name a greater number of other men as coalition partners $(\mathrm{OR}=1.01, \mathrm{CI}=[1.00-$ 1.01]). There was no substantial tendency for individuals to preferentially nominate others who were similar to themselves (i.e. homophily), whether in physical formidability $(\mathrm{OR}=1.21, \mathrm{CI}=$ $[0.79-1.85])$ or in status $(\mathrm{OR}=1.26, \mathrm{CI}=[0.86-1.86])$.

The village corregidor was less likely to be named as a coalition partner during time period one $(\mathrm{OR}=0.47$, CI $-[0.34-0.65])$, but was more likely to be named as a coalition partner during time period two $(\mathrm{OR}=3.94, \mathrm{CI}=[2.07-7.51])$. Over the entire period of observation, the corregidor had no greater likelihood of naming others as coalition partners $(\mathrm{OR}=0.68, \mathrm{CI}=[0.43-1.12])$. 
We further assessed our predictions by analysing coalition and conflict ties at a single time point in a second Tsimane community. For our cross-sectional analyses we specified a stationary SAOM, whereby we assume that the network is in short-term dynamic equilibrium and, thus, we use the same observed network as both the start and end point of observation, and fix our rate parameter to a reasonably high number so that the simulation can reach an equilibrium state. See Snijders et al. (2010) and Snijders and Steglich (2015) for detailed overviews. We included comparable parameters in our longitudinal analyses, and our cross-sectional results were generally qualitatively similar to our longitudinal results. See Supplementary Materials for full details of our cross-sectional analyses and results.

\section{Discussion}

In group-living animals, coalition formation helps individuals resolve interpersonal conflicts in their favour, gain status, suppress or wield dominance and gain advantage in inter-group encounters (Bissonnette et al., 2015). Studying inter-individual coalition formation in human societies is complicated by the formal institutions, such as schools, businesses, courts and governments, that structure social relationships and conflict resolution. We evaluated coalition formation in a small-scale human society where conflict resolution and politics in general remain largely informal. In two communities of the Tsimane people of lowland Bolivia, we described the inter-personal conflicts that tend to arise between men, and we examined several predictions regarding the coalitional support that men receive in the event of conflicts.

Our longitudinal analysis, spanning three waves of data collection in one village $(2009,2014$ and 2017), generally support our predictions. We find evidence that men reciprocate nomination of each other as coalition partners, and we find evidence in support of structural balance theory (Heider, 1982; Rawlings \& Friedkin, 2017). In particular, we find evidence of transitivity, whereby an ally of a man's ally is likely to become his ally as well. Transitivity in coalition formation is not unique to humans. For example, proximity networks in a community of bottlenose dolphin have been shown to be similarly patterned by transitivity (Christakis, 2019; Lusseau, 2003). Why transitivity structures coalition formation may be due to lower transaction costs when building a relationship with an ally's ally, greater probability of shared interests when allying with an ally's ally or greater coalitional synergy. Multiple studies indicate that the level of connectedness among one's supporters increases the perceived social support that one receives from them (Lee et al., 2020). Probably for similar reasons, we find evidence that men in separate conflicts with the same individual are likely to become allies, albeit only in the second period of our longitudinal analysis (2014-2017).

We predicted and found effects of kinship, and of existing sharing relationships on men's subsequent coalition formation. The effect of the latter was more substantial in the second period of the longitudinal analysis. While exchange of food associates with coalitionary support in chimpanzees (Nishida et al., 1992), and in other small-scale human societies with pronounced within- and betweencommunity coalitionary competition (Patton, 2005), it is unlikely that exchange of food and labour is primarily motivated by coalition formation in the Tsimane context. We suggest that it is more likely that Tsimane men provide coalitional support to their exchange partners in order to increase the probability that the exchange relationship continues, although we do not test this possibility. In general, analysing the interactions of multiple social networks over time can greatly improve our understanding of how relationships form (Atkisson et al., 2020; Boccaletti et al., 2014; De Bacco et al., 2017; Kivelä et al., 2014).

We also predicted and found that individuals of higher social status in terms of influence and respect were more likely to be named as sources of coalitional support over time. This result is consistent with a dependence of status on providing aid to others, particularly in societies like the Tsimane where status hierarchy is relatively informal and access to material wealth is limited (Baldassarri \& Grossman, 2013; von Rueden et al., 2019). We also found that status-similar individuals are not more likely to become coalition partners. It is likely that higher status individuals target lower status 
individuals with coalitional support, in part to legitimate or increase their political influence. Lower status individuals may target higher status individuals with coalitional support to increase the efficacy of their coalition and to gain status themselves. We previously showed in this community that foodand labour-sharing also shows a lack of status homophily, individuals gain status in proportion to the status of their sharing partners and higher status men gave and received more food and labour over time (von Rueden et al., 2019). In the present analysis, however, higher status men reported receiving coalitional support from a greater number of men only in time period 1. In time period 2, higher status men reported receiving coalitional support from fewer other men.

We also found preliminary support for the prediction that high status men are more likely to be identified as a source of conflict. However, the descriptive associations we report between status and receipt of conflict nominations must be interpreted with caution, as we did not model conflict as a dependent network with the full suite of covariates that we analyse for the coalition network. It may be that high status men experience more conflict simply because they also have more foodand labour-sharing partnerships, in which conflicts of interest can arise, or because they have more coalition ties, which increases the opportunity to get pulled into conflict. It is also possible that higher status men are more likely to get drawn into conflicts because they are more likely to step in as mediators (Glowacki \& von Rueden, 2015), or higher status men may act more entitled or otherwise provoke conflict owing to envy or dissatisfaction in men with less influence, consistent with conflict as a levelling mechanism (Boehm, 1999).

Physically formidable men reported receiving coalitional support from a greater number of other men, and they were more likely to be named as a source of coalitional support in the first period of our study, although the effects are small. The former result is consistent with evidence in non-human primates (Silk, 1999; Perry et al., 2004; Young et al., 2014) and experimental work in humans (Benenson et al., 2009; Barbaro et al., 2018), which suggests that competitive ability increases one's market value as a coalition partner. Targeting physically formidable men with coalitional support may increase the probability of gaining their coalitionary support in the future.

The time heterogeneity of several of our effects may be attributed in part to the presence of an exogenous shock, severe flooding, in the months prior to data collection in 2014. The flooding substantially limited food production and potential social interactions, as reflected in a large drop in average number of sharing partner nominations in 2014. It may be that in the months and years post-flooding, cooperation in general became more concentrated among those with stronger existing investments in each other's welfare. If so, this could explain why, in period 2, sharing relationships were even more predictive of coalitional support yet high status was less predictive of naming others as providing coalitional support. Greater demands may also have been placed on leadership postflooding. While the community corregidor was named the most frequently as a source of coalitional support at each wave of data collection, only in period 2 did we see a substantial temporal effect in our full model while conditioning on the corregidor's other attributes and social relationships. Interpretation of this effect is complicated, as the corregidor position changed hands at each time point, and thus it is important to note that the effect is assessing the effect of being a corregidor in an observed time on predicting future provision of coalitional support. Our time heterogeneous effects may also be caused by the different time intervals between our measurement points. The amount of time that lapsed during period 1 ( 5 years) is different from the time that lapsed during period 2 (3 years). If the association that sharing has with coalition formation decreases over time, for example, that probably helps to explain why the association is stronger in period 2. In general, our time heterogeneous effects emphasize the value of longitudinal studies, which can link changes in behavioural dynamics to changes in context.

Our cross-sectional results in a second Tsimane community largely corroborate our longitudinal results (See Supplementary Materials). In this second community, coalition ties were more likely between close kin, between individuals with a food- or labour-sharing relationship and between men in conflict with the same other individual. Coalition ties were structured by reciprocity and by transitivity, and higher status and more physically formidable men were more likely to be named 
as sources of coalitional support. In contrast to the longitudinal results, we found no evidence of a so-called Matthew effect, where an individual's popularity as a coalition partner propagates their future popularity. Also in contrast to the longitudinal results, men similar in status and in physical formidability were more likely to have a coalition tie. Perhaps the more equal distribution of status across men in this second community (Glowacki \& von Rueden, 2015) contributes to these results. However, the cross-sectional results speak less to the mechanisms guiding coalition formation than to describing the concurrent distribution of coalition ties.

Quantitative analysis of men's coalitions in other small-scale societies has tended to focus on coalition formation in the context of inter-group raiding. In a study of Nyangatom pastoralists, friendship ties but not physical size predicted joining a raid across various model specifications (Glowacki et al., 2016). Raid leaders were less likely to provoke their friends to join the raid, relative to non-leader participants, perhaps akin to the stronger effect of sharing partnerships than status in predicting coalition ties in the present study. In the Nyangatom, siblings were not more likely to join a raid together, and a similar lack of close consanguineal kinship in raiding party formation has been documented in the Yanomamo (Macfarlan et al., 2014). Moreover, Macfarlan et al. (2014) identified co-participation in raiding as a source of long-term alliance building via marriage. Thus, kinship - particularly affinal kinship - was more a consequence than a cause of raiding party formation. The bidirectional relationship between intra-group coalition formation and inter-group conflict deserves more systematic study cross-culturally.

\section{Limitations}

The small number of conflict nominations and low temporal stability of the conflict network preclude our ability to analyse conflicts as an outcome, rather than only as a predictor of coalition ties. Furthermore, our data do not specify which of individuals' nominated coalition partners actually provided support in the context of the specific conflicts they reported. Nor does our data indicate who individuals' believed won or lost their conflicts, if anyone. It may be that individuals who have more coalitional support do not actually have to mobilize their coalition partners to win conflicts. What may be most important is that others know that they could mobilize a large coalition. Indeed, a study of village 1 in 2005 found that men with more kin and allies were perceived by their peers as more capable of winning a dyadic fight or getting their way in a small group, independent of their physical strength (von Rueden et al., 2008).

Given the risks of over-parameterizing our model, and the absence of theoretical motivation, we do not parse different categories of kinship or food-and-labour sharing, nor analyse effects of weaker kin ties, nor analyse their relationship to our transitivity effect. Beyond the dyad, there are many causal routes by which our covariates could contribute to transitivity in coalition ties. To illustrate the most simple example in terms of kinship (limited to triadic configurations, i.e. three potential individuals), it may be that men prefer kin of kin as a coalition partner, prefer their kin's non-kin coalition partner as a coalition partner or prefer kin of a non-kin coalition partner as a coalition partner, among other possibilities.

We restricted our analysis to men's coalition formation as we presently lack longitudinal data on women's coalitions and conflicts. There is reason to analyse coalition networks separately by gender, given evidence of gender differences in how men and women build and leverage their social relationships, in industrialized societies (Benenson, 2019; David-Barrett et al., 2015; Dunbar, 2018; Friebel et al., 2017; Liesen, 2013; Vigil, 2007) and in small-scale societies with more pronounced gender division of labour (D'Exelle \& Holvoet, 2011; Kasper \& Mulder, 2015; Bliege Bird \& Power, 2015; von Rueden et al., 2018). In the Tsimane, a previous cross-sectional analysis of village 1 found that social relationships beyond the extended family are relatively gender segregated - men tend to have more cooperation partners than women, men tend to cooperate in larger groups and a much larger fraction of men's cooperation partners are same-sex and non-kin (von Rueden et al., 2018). Furthermore, Tsimane men play a more conspicuous role in community politics, but women may gain influence through alternative strategies, such as leading collective action at the extended household level or gaining influence more broadly via gossip or via the making of the alcoholic drink (chicha) that is the glue 
of social gatherings (von Rueden et al., 2018). A study of two villages in rural southern India found that women likewise are seen as lacking influence, but nevertheless can be as central as men in the village cooperation network (Power \& Ready, 2018). Much more research is needed of women's coalition-building in small-scale societies (e.g. Rucas, 2017), how women's and men's coalitions influence each other (e.g. Bowser and Patton, 2004), and in general how sexual selection and culturally varying norms associated with a gendered division of labour interact in the production of gendered coalition building (von Rueden et al., 2018).

\section{Men's politics in egalitarian societies}

While our results are limited to one cultural context, they have implications for the social dynamics that maintain political egalitarianism among men in many small-scale societies, presently and ancestrally. Among the Tsimane, we find that higher status men are hubs of a large community-wide coalition network, which shows only minimal differentiation into separable coalitions (Figure $2 \mathrm{a}-\mathrm{c}$ ) and with limited homophily by status. Greater isolation of within-network clusters can be a key ingredient for the emergence of stratification in larger communities, when accompanied by the emergence of economic specialization and a division of labour (Henrich \& Boyd, 2008), homophily by status (Dávid-Barrett \& Dunbar, 2014) and ability of elites to deploy defensible resources to effectively prevent revolution (Pandit et al., 2020).

The emergence of social network clustering itself is dependent on the process by which individuals gain and maintain status. Most evolutionary accounts of human egalitarianism emphasize the evolution of group-wide levelling coalitions that suppress individual attempts to dominate others, resulting in a 'reverse dominance hierarchy' (Boehm, 1999; Gavrilets et al., 2008). However, dominance relationships are not the only source of status hierarchy, particularly for humans. Prestige-based status became more important as hominins evolved greater interdependence in food production and in raising offspring (Redhead et al., 2019; von Rueden, 2020). Even in the most egalitarian societies, community members will grant greater informal influence to individuals whose generosity, knowledge or leadership generates the most benefits for others (Garfield et al., 2019), including leadership that coordinates the levelling of would-be dominants.

Thus, to maintain status in relatively egalitarian societies, high status individuals are motivated to demonstrate their value by broadly offering support to individuals of lower status than themselves (von Rueden \& Jaeggi, 2016). And as we demonstrated in our previous work with the Tsimane (von Rueden et al., 2019), lower status individuals gain status (i.e. influence and respect) over time as a result of cooperation with higher status individuals. Status can beget more status, especially where status is based on inheritance of material wealth (Mattison et al., 2016; Borgerhoff Mulder et al., 2009). As societies gain greater access to privately accumulable material wealth and status becomes more contingent on such wealth, higher status individuals may lose some incentive to cooperate with lower status individuals (i.e. Kasper \& Mulder, 2015; Thomas et al., 2018). However, in societies like the Tsimane with less market integration, status differentiation is kept in check in part by the dependency of status on cooperation with diverse community members, and the status gains that accrue to lower status individuals who cooperate with higher status individuals (von Rueden et al., 2019). Prestige-driven cooperation dynamics, not just levelling of would-be dominants, maintains human egalitarianism.

Of course, individuals must walk a thin line when offering coalitional support in order to build or maintain status. The highest status individuals in relatively egalitarian societies are those who can strategically deploy coalitional support to build up a community-wide following while simultaneously limiting resentment among individuals who do not get their way. It is not contradictory that high status Tsimane men are seen as providing more coalitional support, are seen as frequent sources of conflict and yet are also more likely to be named as conflict mediators (Glowacki \& von Rueden, 2015). Politics is the art of persuading (just) enough people you have their interests at heart.

Supplementary material. To view supplementary material for this article, please visit https://oi.org/10.1017/ehs.2021.26 
Acknowledgements. We thank the residents of our study communities in Bolivia for their generous participation in this research. We also thank Joseph Kilgallen, Sarah Alami, Dr Paul Hooper and members of the Tsimane Health and Life History Project who helped collect data, and Dr Dieter Lucas, Dr Eleanor Power, Nikkin Devaraju, the Department of Human Behaviour, Ecology and Culture at the Max Planck Institute for Evolutionary Anthropology, and two anonymous reviewers for providing useful feedback and supporting this project.

Author contributions. DR and CvR designed the study. CvR collected the data. DR conducted statistical analyses. DR and CvR wrote the article.

Financial support. Research was supported by grants from the National Science Foundation (BCS-0136274, BCS-0422690, DDIG-0921429) and the National Institutes of Health (R01AG024119-01).

Conflicts of interest. DR and CvR declare none.

Data availability. All relevant data and code for reproducing the analyses and figures are available at https:/github.com/ danielRedhead/coalition-conflict-status.

\section{References}

Aktipis, A., Cronk, L., Alcock, J., Ayers, J. D., Baciu, C., Balliet, D., Boddy, A.M., ... Winfrey, P. (2018). Understanding cooperation through fitness interdependence. Nature Human Behaviour, 2(7), 429-431.

Alden Smith, E. (2003). Human cooperation: Perspectives from behavioral ecology. In Hammerstein P (Ed.), Genetic and cultural evolution of cooperation. MIT Press.

Atkisson, C., Górski, P. J., Jackson, M. O., Hołyst, J. A., \& D’Souza, R. M. (2020). Why understanding multiplex social network structuring processes will help us better understand the evolution of human behavior. Evolutionary Anthropology: Issues, News, and Reviews, 29(3), 102-107.

Baldassarri, D. and Grossman, G. (2013). The effect of group attachment and social position on prosocial behavior. Evidence from lab-in-the-field experiments. PloS one, 8(3), e58750.

Barbaro, N., Mogilski, J. K., Shackelford, T. K., \& Pham, M. N. (2018). Men's interest in allying with a previous combatant for future group combat. Human Nature, 29(3), 328-336.

Benenson, J. F. (2019). Sex differences in human peer relationships: A primate's-eye view. Current Directions in Psychological Science, 28(2), 124-130.

Benenson, J. F., Markovits, H., Emery Thompson, M., \& Wrangham, R. W. (2009). Strength determines coalitional strategies in humans. Proceedings of the Royal Society B: Biological Sciences, 276(1667), 2589-2595.

Bissonnette, A., Perry, S., Barrett, L., Mitani, J. C., Flinn, M., Gavrilets, S., \& de Waal, F. B. (2015). Coalitions in theory and reality: A review of pertinent variables and processes. Behaviour, 152(1), 1-56.

Bliege Bird, R. and Power, E. A. (2015). Prosocial signaling and cooperation among Martu hunters. Evolution and Human Behavior, 36(5), 389-397.

Boccaletti, S., Bianconi, G., Criado, R., Del Genio, C. I., Gómez-Gardenes, J., Romance, M., Sendina-Nadal, I., ... Zanin, M. (2014). The structure and dynamics of multilayer networks. Physics Reports, 544(1), 1-122.

Boehm, C. (1999). Hierarchy in the forest: The evolution of egalitarian behavior. Harvard University Press.

Borgerhoff Mulder, M., Bowles, S., Hertz, T., Bell, A., Beise, J., Clark, G., et al. (2009). Intergenerational wealth transmission and the dynamics of inequality in small-scale societies. Science, 326(5953), 682-688.

Bowser, B. J. and Patton, J. Q. (2004). Domestic spaces as public places: An ethnoarchaeological case study of houses, gender, and politics in the ecuadorian amazon. Journal of Archaeological Method and Theory, 11(2), 157-181.

Broom, M., Koenig, A., \& Borries, C. (2009). Variation in dominance hierarchies among group-living animals: Modeling stability and the likelihood of coalitions. Behavioral Ecology, 20(4), 844-855.

Chapais, B. (2009). Primeval kinship: How pair-bonding gave birth to human society. Harvard University Press.

Christakis, N. A. (2019). Blueprint: The evolutionary origins of a good society. Hachette UK.

Csardi, G., Nepusz, T., et al. (2006). The igraph software package for complex network research. InterJournal: Complex Systems, 1695(5), 1-9.

Dávid-Barrett, T. and Dunbar, R. (2014). Social elites can emerge naturally when interaction in networks is restricted. Behavioral Ecology, 25(1), 58-68.

David-Barrett, T., Rotkirch, A., Carney, J., Izquierdo, I. B., Krems, J. A., Townley, D., .. Dunbar, R. I. (2015). Women favour dyadic relationships, but men prefer clubs: Cross-cultural evidence from social networking. PloS one, 10(3), e0118329.

De Bacco, C., Power, E. A., Larremore, D. B., \& Moore, C. (2017). Community detection, link prediction, and layer interdependence in multilayer networks. Physical Review E, 95(4), 042317.

D'Exelle, B. and Holvoet, N. (2011). Gender and network formation in rural Nicaragua: A village case study. Feminist Economics, 17(2), 31-61. 
Duffy, K. G., Wrangham, R. W., \& Silk, J. B. (2007). Male chimpanzees exchange political support for mating opportunities. Current Biology, 17(15), R586-R587.

Dunbar, R. I. (2018). The anatomy of friendship. Trends in Cognitive Sciences, 22(1), 32-51.

Friebel, G., Lalanne, M., Richter, B., Schwardmann, P., \& Seabright, P. (2017). Women form social networks more selectively and less opportunistically than men. SAFE Working Paper Series 168.

Garfield, Z. H., von Rueden, C., \& Hagen, E. H. (2019). The evolutionary anthropology of political leadership. The Leadership Quarterly, 30(1), 59-80.

Gavrilets, S., Duenez-Guzman, E. A., \& Vose, M. D. (2008). Dynamics of alliance formation and the egalitarian revolution. PLoS One, 3(10).

Gilby, I. C., Brent, L. J., Wroblewski, E. E., Rudicell, R. S., Hahn, B. H., Goodall, J., \& Pusey, A. E. (2013). Fitness benefits of coalitionary aggression in male chimpanzees. Behavioral Ecology and Sociobiology, 67(3), 373-381.

Glowacki, L., Isakov, A., Wrangham, R. W., McDermott, R., Fowler, J. H., \& Christakis, N. A. (2016). Formation of raiding parties for intergroup violence is mediated by social network structure. Proceedings of the National Academy of Sciences, 113(43), 12114-12119.

Glowacki, L. and von Rueden, C. (2015). Leadership solves collective action problems in small-scale societies. Philosophical Transactions of the Royal Society B: Biological Sciences, 370(1683), 20150010.

Glowacki, L., Wilson, M. L., \& Wrangham, R. W. (2017). The evolutionary anthropology of war. Journal of Economic Behavior \& Organization, 178, 963-982.

Harcourt, A. H., de Waal, F. B., \& others (1992). Coalitions and alliances in humans and other animals. Oxford University Press.

Heider, F. (1982). The psychology of interpersonal relations. Psychology Press.

Henrich, J. and Boyd, R. (2008). Division of labor, economic specialization, and the evolution of social stratification. Current Anthropology, 49(4), 715-724.

Hoff, P. (2018). Package 'sbgcop'.

Hollenbach, F. M., Bojinov, I., Minhas, S., Metternich, N. W., Ward, M. D., \& Volfovsky, A. (2018). Multiple imputation using Gaussian copulas. Sociological Methods \& Research, 0049124118799381.

Hooper, P. L., Gurven, M., Winking, J., \& Kaplan, H. S. (2015). Inclusive fitness and differential productivity across the life course determine intergenerational transfers in a small-scale human society. Proceedings of the Royal Society B: Biological Sciences, 282(1803), 20142808.

Hughes, A. L. (1988). Evolution and human kinship. Oxford University Press.

Huisman, M. and Snijders, T. A. (2003). Statistical analysis of longitudinal network data with changing composition. Sociological methods \& research, 32(2), 253-287.

Isakov, A., Fowler, J. H., Airoldi, E. M., \& Christakis, N. A. (2019). The structure of negative social ties in rural village networks. Sociological Science, 6, 197-218.

Kasper, C. and Mulder, M. B. (2015). Who helps and why?: Cooperative networks in mpimbwe. Current Anthropology, 56(5), 701-732.

Kivelä, M., Arenas, A., Barthelemy, M., Gleeson, J. P., Moreno, Y., \& Porter, M. A. (2014). Multilayer networks. Journal of Complex Networks, 2(3), 203-271.

Lee, D. S., Stahl, J. L., \& Bayer, J. B. (2020). Social resources as cognitive structures: Thinking about a dense support network increases perceived support. Social Psychology Quarterly, 0190272520939506.

Liesen, L. (2013). The tangled web she weaves (pp. 43-62). Oxford University Press.

Lospinoso, J. A., Schweinberger, M., Snijders, T. A., \& Ripley, R. M. (2011). Assessing and accounting for time heterogeneity in stochastic actor oriented models. Advances in Data Analysis and Classification, 5(2), 147-176.

Low, B. S. (1992). Sex, coalitions, and politics in preindustrial societies. Politics and the Life Sciences, 11(1), 63-80.

Lusseau, D. (2003). The emergent properties of a dolphin social network. Proceedings of the Royal Society of London B: Biological Sciences, 270(suppl_2), S186-S188.

Macfarlan, S. J., Walker, R. S., Flinn, M. V., \& Chagnon, N. A. (2014). Lethal coalitionary aggression and long-term alliance formation among Yanomamö men. Proceedings of the National Academy of Sciences, 111(47), 16662-16669.

Mattison, S. M., Smith, E. A., Shenk, M. K., \& Cochrane, E. E. (2016). The evolution of inequality. Evolutionary Anthropology: Issues, News, and Reviews, 25(4), 184-199.

McDonald, M. M., Navarrete, C. D., \& Van Vugt, M. (2012). Evolution and the psychology of intergroup conflict: The male warrior hypothesis. Philosophical Transactions of the Royal Society B: Biological Sciences, 367(1589), 670-679.

Nishida, T., Hasegawa, T., Hayaki, H., Takahata, Y., \& Uehara, S. (1992). Meat-sharing as a coalition strategy by an alpha male chimpanzee. Topics in Primatology, 1, 159-174.

Pandit, S. A., Pradhan, G. R., \& Van Schaik, C. P. (2020). Why class formation occurs in humans but not among other primates. Human Nature, 31(2), 155-173.

Pandit, S. A. and van Schaik, C. P. (2003). A model for leveling coalitions among primate males: Toward a theory of egalitarianism. Behavioral Ecology and Sociobiology, 55(2), 161-168.

Patton, J. Q. (2005). Meat sharing for coalitional support. Evolution and human behavior, 26(2), 137-157. 
Perry, S., Barrett, H. C., \& Manson, J. H. (2004). White-faced capuchin monkeys show triadic awareness in their choice of allies. Animal Behaviour, 67(1), 165-170.

Pietraszewski, D. (2016). How the mind sees coalitional and group conflict: The evolutionary invariances of n-person conflict dynamics. Evolution and Human Behavior, 37(6), 470-480.

Power, E. A. and Ready, E. (2018). Building bigness: Reputation, prominence, and social capital in rural South India. American Anthropologist, 120(3), 444-459.

Rawlings, C. M. and Friedkin, N. E. (2017). The structural balance theory of sentiment networks: Elaboration and test. American Journal of Sociology, 123(2), 510-548.

Redhead, D. J., Cheng, J. T., Driver, C., Foulsham, T., \& O'Gorman, R. (2019). On the dynamics of social hierarchy: A longitudinal investigation of the rise and fall of prestige, dominance, and social rank in naturalistic task groups. Evolution and Human Behavior, 40(2), 222-234.

Reyes-García, V., Díaz-Reviriego, I., Duda, R., Fernández-Llamazares, Á., Gallois, S., Guèze, M., ... Pyhälä, A. (2016). Peer evaluation can reliably measure local knowledge. Field methods, 28(4), 345-362.

Ripley, R. M., Snijders, T. A., Boda, Z., Vörös, A., \& Preciado, P. (2020). Manual for Rsiena. University of Oxford, Department of Statistics, Nuffield College.

Robins, G., Pattison, P., \& Wang, P. (2009). Closure, connectivity and degree distributions: Exponential random graph ( $\mathrm{p}^{*}$ ) models for directed social networks. Social Networks, 31(2), 105-117.

Rosvall, M., Axelsson, D., \& Bergstrom, C. T. (2009). The map equation. The European Physical Journal Special Topics, 178 (1), 13-23.

Rosvall, M. and Bergstrom, C. T. (2008). Maps of random walks on complex networks reveal community structure. Proceedings of the National Academy of Sciences, 105(4), 1118-1123.

Rucas, S. L. (2017). Cooperation drives competition among tsimane women in the Bolivian Amazon. In The Oxford Handbook of Women and Competition (pp. 1693-1720). Oxford University Press.

Silk, J. B. (1999). Male bonnet macaques use information about third-party rank relationships to recruit allies. Animal Behaviour, 58(1), 45-51.

Smuts, B. (1995). The evolutionary origins of patriarchy. Human Nature, 6(1), 1-32.

Snijders, T. A. (1996). Stochastic actor-oriented models for network change. Journal of Mathematical Sociology, 21(1-2), 149172.

Snijders, T. A. and Steglich, C. E. (2015). Representing micro-macro linkages by actor-based dynamic network models. Sociological Methods \& Research, 44(2), 222-271.

Snijders, T. A., Van de Bunt, G. G., \& Steglich, C. E. (2010). Introduction to stochastic actor-based models for network dynamics. Social Networks, 32(1), 44-60.

Stibbard-Hawkes, D. N., Attenborough, R. D., \& Marlowe, F. W. (2018). A noisy signal: To what extent are hadza hunting reputations predictive of actual hunting skills? Evolution and Human Behavior, 39(6), 639-651.

Szell, M., Lambiotte, R., \& Thurner, S. (2010). Multirelational organization of large-scale social networks in an online world. Proceedings of the National Academy of Sciences, 107(31), 13636-13641.

Team, R. C. (2013). R: A language and environment for statistical computing.

Thomas, M. G., Ji, T., Wu, J., He, Q., Tao, Y., \& Mace, R. (2018). Kinship underlies costly cooperation in mosuo villages. Royal Society Open Science, 5(2), 171535.

Tokuyama, N. and Furuichi, T. (2016). Do friends help each other? Patterns of female coalition formation in wild bonobos at Wamba. Animal Behaviour, 119, 27-35.

Tomasello, M., Carpenter, M., Call, J., Behne, T., \& Moll, H. (2005). Understanding and sharing intentions: The origins of cultural cognition. Behavioral and Brain Sciences, 28(5), 675-691.

Tooby, J., Cosmides, L., \& Price, M. E. (2006). Cognitive adaptations for $n$-person exchange: The evolutionary roots of organizational behavior. Managerial and Decision Economics, 27(2-3), 103-129.

Van Schaik, C. P. (1989). The ecology of social relationships amongst female primates. Comparative Socioecology, $195-218$.

Vigil, J. M. (2007). Asymmetries in the friendship preferences and social styles of men and women. Human Nature, 18(2), 143-161.

von Rueden, C. (2020). Making and unmaking egalitarianism in small-scale human societies. Current Opinion in Psychology, 33, 167-171.

von Rueden, C., Alami, S., Kaplan, H., \& Gurven, M. (2018). Sex differences in political leadership in an egalitarian society. Evolution and Human Behavior, 39(4), 402-411.

von Rueden, C. R., Gurven, M., \& Kaplan, H. (2008). The multiple dimensions of male social status in an Amazonian society. Evolution and Human Behavior, 29(6), 402-415.

von Rueden, C., Gurven, M., Kaplan, H., \& Stieglitz, J. (2014). Leadership in an egalitarian society. Human Nature, 25(4), 538-566.

von Rueden, C. R. and Jaeggi, A. V. (2016). Men's status and reproductive success in 33 nonindustrial societies: Effects of subsistence, marriage system, and reproductive strategy. Proceedings of the National Academy of Sciences, 113(39), 10824-10829. 
von Rueden, C. R., Redhead, D., O’Gorman, R., Kaplan, H., \& Gurven, M. (2019). The dynamics of men's cooperation and social status in a small-scale society. Proceedings of the Royal Society B: Biological Sciences, 286(1908), 20191367.

Walker, R. S., Beckerman, S., Flinn, M. V., Gurven, M., von Rueden, C. R., Kramer, K. L., et al. (2013). Living with kin in lowland horticultural societies. Current Anthropology, 54(1), 96-103.

Watts, D. (2002). Reciprocity and interchange in the social relationships of wild male chimpanzees. Behaviour, 139(2), 343-370.

Watts, D. P. (2018). Male dominance relationships in an extremely large chimpanzee community at Ngogo, Kibale National Park, Uganda. Behaviour, 155(13-15), 969-1009.

Werner, D. (1981). Are some people more equal than others? status inequality among the Mekranoti Indians of central Brazil. Journal of Anthropological Research, 37(4), 360-373.

Wiessner, P. (2005). Norm enforcement among the Ju/'hoansi bushmen. Human Nature, 16(2), 115-145.

Young, C., Schülke, O., \& Ostner, J. (2014). How males form coalitions against group rivals and the pandit/van schaik coalition model. Behaviour, 151(7), 907-934.

Cite this article: Redhead D, von Rueden CR (2021). Coalitions and conflict: A longitudinal analysis of men's politics. Evolutionary Human Sciences 3, e31, 1-20. https://doi.org/10.1017/ehs.2021.26 